\title{
Correction to: HCI in Business, Government and Organizations
}

Fiona Fui-Hoon Nah and Keng Siau

\section{Correction to: \\ F. F.-H. Nah and K. Siau (Eds.): \\ HCI in Business, Government and Organizations, LNCS 12204, https://doi.org/10.1007/978-3-030-50341-3}

The chapter 10 was inadvertently published with an error in the name of the fourth author as Andrew McCubbins. The first name of the author was corrected.

The chapter 36 was inadvertently published with an error in the affiliation of the second author as "ISEM Fashion Business School, University of Madrid, Madrid, Spain". The name of the affiliation was corrected.

The updated version of these chapters can be found at https://doi.org/10.1007/978-3-030-50341-3_10

https://doi.org/10.1007/978-3-030-50341-3_36

(C) Springer Nature Switzerland AG 2020

F. F.-H. Nah and K. Siau (Eds.): HCII 2020, LNCS 12204, p. C1, 2020.

https://doi.org/10.1007/978-3-030-50341-3_43 